\title{
An Apparatus for Measuring Thermal Expansion at Elevated Temperatures
}

\author{
B. D. Rothrock and R. K. Kirby \\ Institute for Basic Standards, National Bureau of Standards, Washington, D.C. 20234
}

(November 23, 1966)

\begin{abstract}
An apparatus has been developed for making precise measurements of the absolute thermal expansion of refractory materials at temperatures up to $1600{ }^{\circ} \mathrm{C}$. This apparatus consists of an optical comparator and a controlled gradient vacuum furnace. Special care was taken on the techniques of measuring length and temperature and on the calibration of the microscopes and thermometers. The expansion data obtained with this apparatus on specimens of platinum and sapphire have a standard deviation of less than $30 \mathrm{ppm}$ and are estimated to be accurate to within $50 \mathrm{ppm}$.
\end{abstract}

Key Words: Controlled-gradient vacuum furnace, elevated temperatures, optical comparator, thermal expansion.

\section{Introduction}

Accurate data on the thermal expansion of solids at temperatures above $1000{ }^{\circ} \mathrm{C}$ are needed for several reasons. (1) They are needed on at least one reproducible material so that engineering data on other materials can be obtained with relatively simple apparatus by a comparison method [1]. ${ }^{1}$ (2) The material on which the data is obtained can be used to measure temperatures in high-temperature x-ray diffraction cameras and diffractometers [2,3]. (3) Accurate high-temperature data can be useful in the study of lattice defect formation [4], phase transitions [5], and the theory of thermal expansion $[4,6]$. The apparatus described in this paper was constructed primarily to furnish accurate thermal expansion data up to $1600{ }^{\circ} \mathrm{C}$ on a reference material that could be used by others in measuring thermal expansion. Because of this, special care was taken on the techniques of measuring length and temperature and on the construction of the furnace.

An optical comparator method was chosen because it can be used to make accurate and precise measurements of the expansion of solid material at elevated temperatures. The present method makes use of a pair of microscopes mounted on an invar bar and each measurement of the length of the specimen is compared to the length of a reference bar kept at room temperature. This procedure gives a correction that compensates for any apparent change in distance between the microscopes caused by the expansion of

${ }^{1}$ Figures in brackets indicate the literature references at the end of this paper. the invar bar or the tilting of the microscopes. The nominal length of the specimen between the fiducial marks is $10 \mathrm{~cm}$. The specimen, hung vertically in the furnace, is free of all restraint so that measurements of expansion will be accurate as long as the specimen does not creep significantly under its own weight. The vacuum furnace is specially designed to correct for end heat losses. In addition the temperature profile over the length of the specimen was measured with a calibrated probe thermocouple. A detailed description of the apparatus and techniques is given in the following sections.

\section{Apparatus}

\subsection{Furnace}

To make accurate length versus temperature measurements the furnace must be designed and constructed to produce a uniform temperature along the length of the specimen or the temperature gradient along the specimen length must be known at each temperature to determine the effective or average temperature of the specimen [7]. To obtain a uniform temperature over the specimen length a controlledgradient furnace was constructed that has five individually controlled heating sections obtained by tapping an evenly wound resistance heater at $5 \mathrm{~cm}$ intervals. By the use of isolation transformers the power in any one section can be controlled with only a negligible change in power in the remaining sections. This design, as shown in figure 1 , makes it possible to adjust the power input at any temperature to com- 


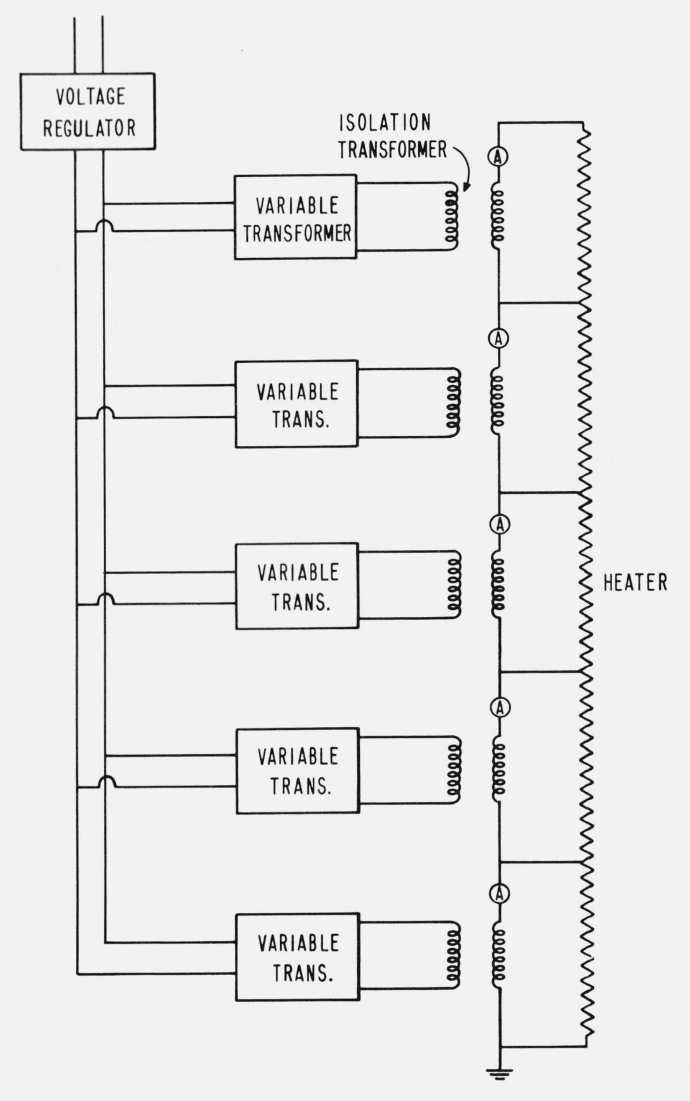

Figure 1. Schematic diagram of heater control circuit.

pensate for end heat losses. A voltage regulator was used to compensate for line voltage variations as it was felt that this would be the main cause of temperature variations. The power required to obtain $1600{ }^{\circ} \mathrm{C}$ was $2.6 \mathrm{~kW}$.

The heater wire, having a diameter of about $1 \mathrm{~mm}$, is wound about a core in a $1.6 \mathrm{~mm}$ deep continuous groove, 6 revolutions per $25.4 \mathrm{~mm}$. Tantalum, tungsten, and rhenium wire have been used. Although each have desirable resistivity and high temperature properties, rhenium proved to be the best because of its high-temperature inertness and greater ability to be worked.

The high-purity alumina $\left(99 \% \mathrm{Al}_{2} \mathrm{O}_{3}\right)$ core on which the heater is wound is $30.5 \mathrm{~cm}$ long and has a 1.91 $\mathrm{cm}$ I.D. and a $2.54 \mathrm{~cm}$ O.D. Sight holes, $6.3 \mathrm{~mm}$ in diameter, in the core, see figure 2 , are alined with holes in the heat shields and the windows in the outer shell. Two windows on one side, with centers 10 $\mathrm{cm}$ apart, allow viewing of the specimen for length measurements. A third window on the opposite side permits temperature measurements with an optical pyrometer.

The specimen, a 12 to $14-\mathrm{cm}$ rod having a diameter of about $5 \mathrm{~mm}$, is hung from the top of the furnace by two loops of tungsten wire. The small lower loop runs through a small hole in the top of the specimen and is connected to the larger upper loop by a tungsten joint which allows the specimen to hang freely in a vertical position. Vertical, lateral, and rotational movement can be achieved through a bellows and vacuum seal.

The control and measuring thermocouples are positioned in $0.76 \mathrm{~mm}$ holes in the wall of a high-purity alumina tube. This tube, $1.11 \mathrm{~cm} \mathrm{I.D.} \mathrm{by} 1.75 \mathrm{~cm}$ O.D., is $35.6 \mathrm{~cm}$ in length. The thermocouples are shielded by a grounded rhenium foil placed between the heating core and thermocouple protection tube. A small a-c pickup can be detected but did not affect the thermocouple emf output as read by either the potentiometer or recorder.

The outer stainless steel shell of the furnace is water-cooled and vacuum sealed. The vacuum system consists of a fore pump, oil diffusion pump, watercooled baffle, and vacuum gages. The vacuum gage indicator, power supply and controls, and temperature indicators are mounted in a relay rack.

\subsection{Comparator and Reference Scale}

The comparator shown in figure 3 , consisting of two microscopes mounted on an invar bar, was obtained commercially. The microscopes have filar micrometer eyepieces, 50× magnification, and relay lenses which allow a working distance of $16 \mathrm{~cm}$. They can be raised or lowered and rotated about a vertical axis. The comparator, however, was modified to allow for precise alinement after being rotated between the specimen and scale positions.

The reference scale, mounted outside the furnace, is made by wrapping a $0.020 \mathrm{~mm}$ tungsten wire about a vitreous-silica rectangular bar $2.54 \mathrm{~cm} \times 1.91$ $\mathrm{cm} \times 15.2 \mathrm{~cm}$. The wires are spaced $1 \mathrm{~mm}$ apart by grooves at the edges of the silica bar and held in position by epoxy. The back surface of the clear bar was ground so that when illuminated from the back the wires stood out sharply against an evenly illuminated field. The scale was calibrated accurately to within \pm 0.2 micrometers by using a line standard, Decimeter No. 43, provided by the Length Section of the National Bureau of Standards. The position of the scale can be adjusted in the vertical and horizontal directions.

The scale eliminates any apparent or real shift in the measurement of length caused by expansion of the invar bar or tilting of the microscopes and establishes the absolute length of the specimen. In preliminary tests on the microscopes, measurements were made on the reference scale while changing the ambient room temperature. These tests disclosed that one of the microscopes was tilting in its mount and might have contributed an error in length measurements of about 100 micrometers/meter. The mount was remachined and provided no further difficulty. This experience emphasizes the usefulness of a reference scale for if the defective mount had not been detected the use of the scale would have automatically corrected the length measurements.

The microscopes were alined and calibrated by first adjusting the invar bar on which the microscopes are mounted to the vertical position. Next, the micro- 


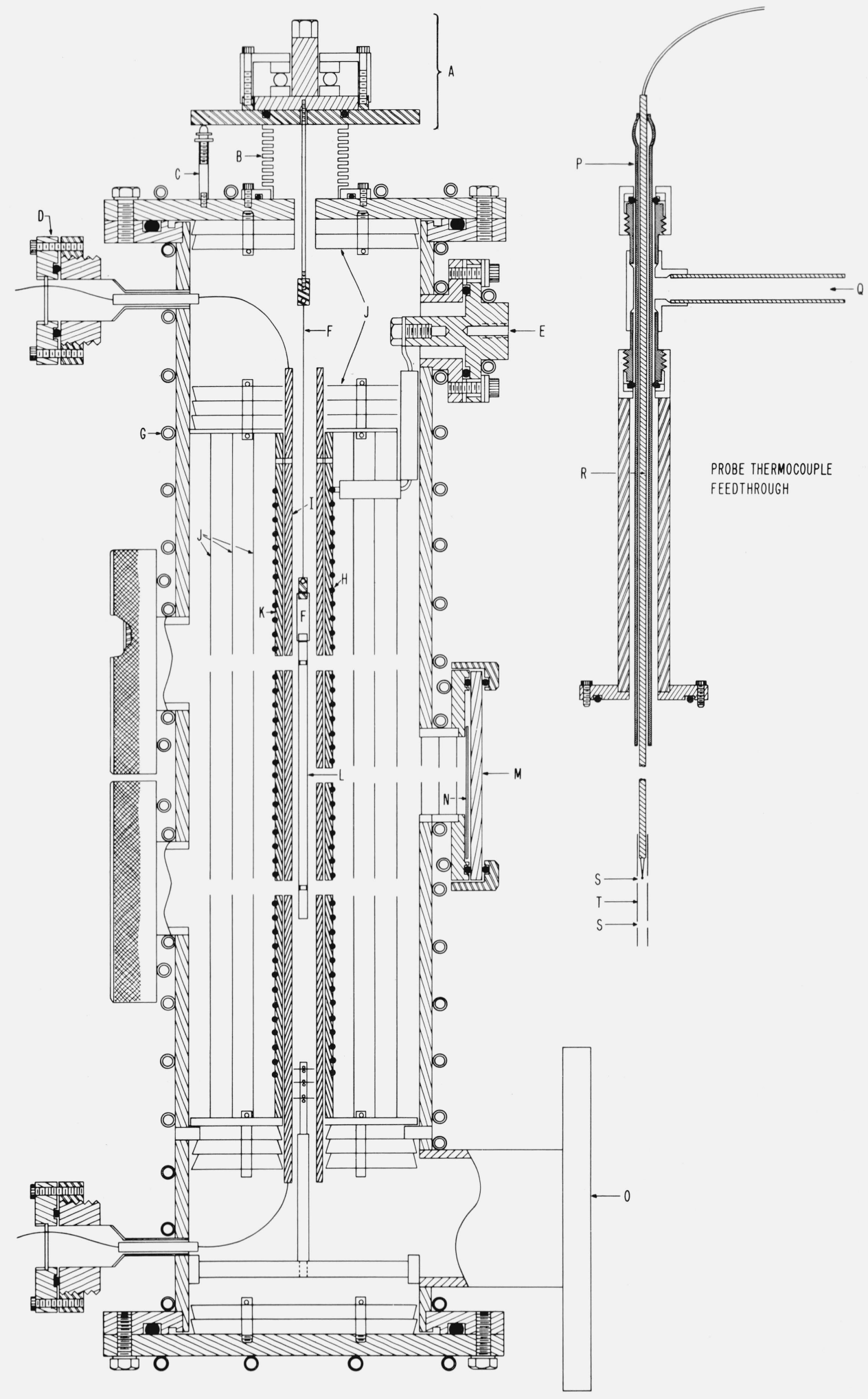

FIGURE 2. Controlled gradient vacuum furnace and probe thermocouple feedthrough.

A. Specimen support
B. Bellows
C. Position adjusting screw, one of three
D. Thermocouple feedthrough
E. Electrical feedthrough, one of ten
F. Tungsten wire loop
G. Water cooling coil
H. Resistance heating wire
I. Thermocouple protection tube

J. Radiation heat shields

K. Alumina core

L. Specimen

M. Window

O. Vacuum port
P. Vicor tube

Q. Vacuum

R. Thermocouple protection tube

S. Pyrometer viewing hole

T. Tantalum tube. 


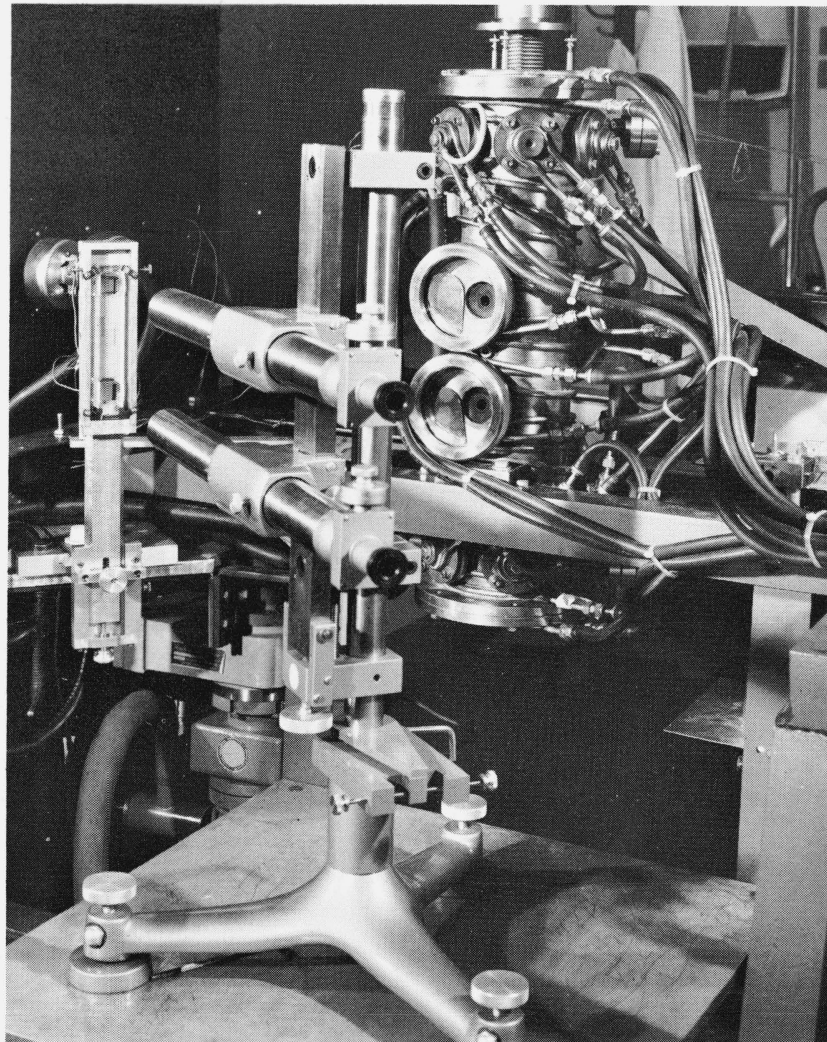

FIGURE 3. Photograph showing relative position of comparator, furnace and reference scale.

scope tubes were adjusted until they were horizontal and parallel. The microscopes were then moved in their individual mounts until they were both focused on a freely hanging $0.38 \mathrm{~mm}$ wire. The paired microscopes were turned toward the reference scale and the position of the scale was adjusted until it was focused in each microscope. With the microscopes focused on the scale each eyepiece was calibrated by measuring the separation of two wires. After many repeated measurements the values for the eyepieces were determined to be 1.128 and 1.095 micrometers per division.

\section{Control and Measurement Techniques}

\subsection{Temperature}

To control the temperature gradient in the furnace four differential W-Re thermocouples were placed in the thermocouple protection tube. One of the junctions of each of the thermocouples was placed at the center of the furnace and the other junction was placed at the center of one of the other four heating sections. This provides a comparison of temperature at the center of each heating section with the temperature at the center of the furnace.

A multipoint strip chart recorder is used to record the output of the differential thermocouples. The recorder scale is zero centered with a full scale deflection of $\pm 300 \mu \mathrm{V}$ (10 $\mu \mathrm{V}$ per scale division). The plot can be read to better than 1 scale division and hence the differential temperature to better than $1{ }^{\circ} \mathrm{C}$. The 24-second printing cycle of the recorder is about the response time of the furnace to a power change. Using this system it is not difficult to maintain a gradient within $\pm 2{ }^{\circ} \mathrm{C}$ as indicated by the recorder. In the time it takes to make a set of readings the average temperature usually did not vary more than $\pm 1{ }^{\circ} \mathrm{C}$.

To test the actual temperature profile at the position occupied by the specimen an arrangement was made for measuring the temperature with a single absolute thermocouple. This probe thermocouple was inserted into the furnace through the top plate by means of a sliding vacuum seal, see figure 2 . The wires were insulated with a two-hole high-purity alumina protection tube. The junction was about $5 \mathrm{~mm}$ below the end of the alumina tube but was shielded by a thinwalled 4-mm O.D. tantalum tube. The tantalum tube extended about $3 \mathrm{~cm}$ above and below the junction and had two small holes in it to allow the optical pyrometer to "see" the junction when it was located at the center of the furnace and to use the tube as a blackbody when the junction was located slightly above the center of the furnace.

The probe thermocouple measured the temperature profile along the axis of the furnace at several different temperatures. At each temperature the current in each heating section was adjusted until the print out on the strip chart recorder indicated that all four differential thermocouples were at the same temperature. The probe thermocouple was then raised and lowered and readings taken at $1 \mathrm{~cm}$ intervals. As shown in figure 4 , the actual temperature profile has an overall slope with dips at the viewing windows. This same slope was found when the probe thermocouple was inserted into the furnace through the bottom plate. The temperature profile that is obtained when each heating section has the same current flowing through its heating element is also shown in figure 4.

Temperature measurements are made at the center of the furnace with a W-Re thermocouple and a Pt-Rh 30-6 thermocouple placed in the thermocouple protection tube. These thermocouples and the optical pyrometer were calibrated by comparison with a probe thermocouple that had been calibrated by the Temperature Physics Section of the National Bureau of Standards. During this calibration the probe thermocouple was at a point $2 \mathrm{~cm}$ above the center of the furnace where the slope of the temperature profile was nearly zero. The value of the average temperature and its position was determined from the temperature profile over the specimen length. A correction was made to the indication of the probe thermocouple corresponding to the difference between the average temperature and the temperature at the $2 \mathrm{~cm}$ position as taken from the temperature profile.

Because the thermocouples were calibrated with the probe thermocouple occupying the same space that the specimen occupies during an expansion test, 


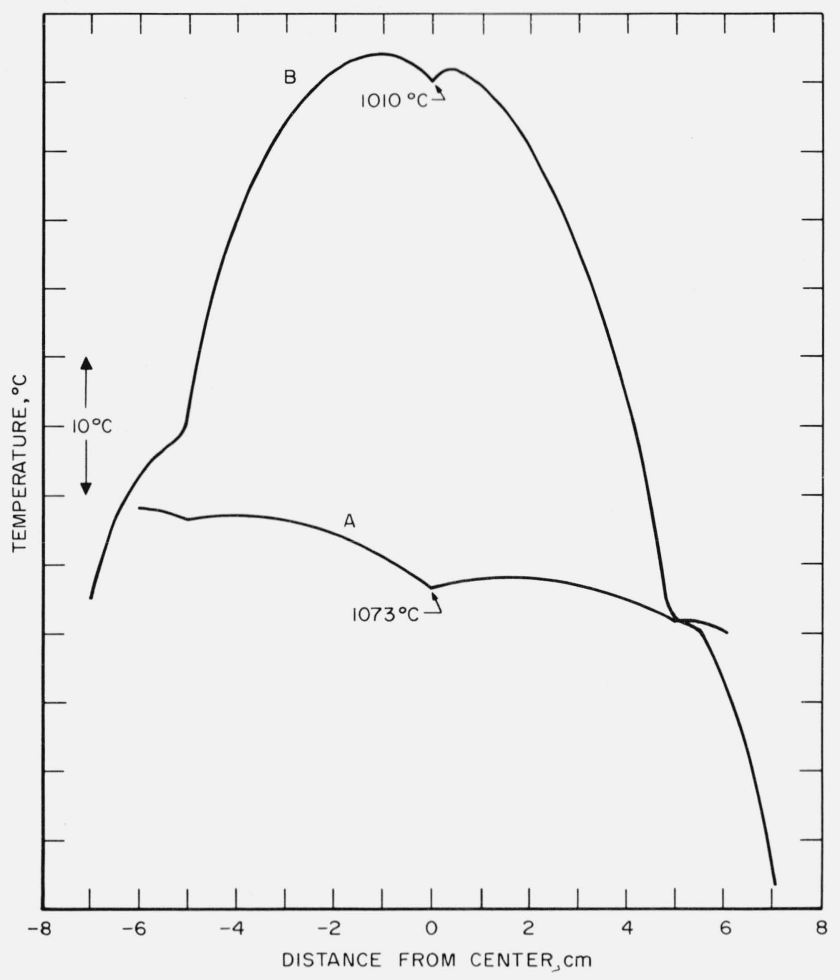

FIGURE 4. Temperature profile along the axis of the furnace top of furnace to right): A, current adjusted in each heating section until all four differential thermocouples were at the same temperature; $B$, same current flowing through each heating section.

it is assumed that the temperature measurements accurately represent the temperature within the specimen.

While the temperature measurements made with the optical pyrometer and the thermocouples were usually in reasonable agreement, within $\pm 3{ }^{\circ} \mathrm{C}$, the measurements made with the pyrometer were only used as an additional check on the thermoucouples. After the furnace had been heated above $1500{ }^{\circ} \mathrm{C}$, slight deposits could be seen on the windows and the temperature measurements made with the pyrometer would be as much as $50{ }^{\circ} \mathrm{C}$ lower than those made with the thermocouples.

\subsection{Length}

In order to obtain reliable measurements of length the fiducial marks should be an integral part of the specimen or not subject to arbitrary shifts. In order to obtain measurements of high precision the fiducial marks should be small (of the order of $0.025 \mathrm{~mm}$ when using a magnification of $50 \times$ ), symmetrical, and capable of forming an image with sharp focus. Several experimenters $[8,9,10]$ have used fiducial marks made by peening small wires into holes drilled into the specimen, clipping the wires off close to the specimen and placing nicks in the resulting sharp edge. Other investigators have used marks scribed or indented into the surface of the specimen [4] or sighted on the ends of the specimen $[11,12]$.

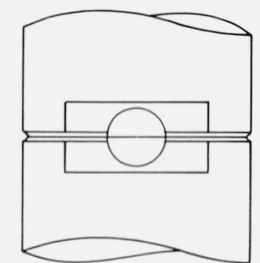

(a)

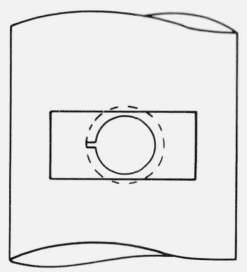

(b)
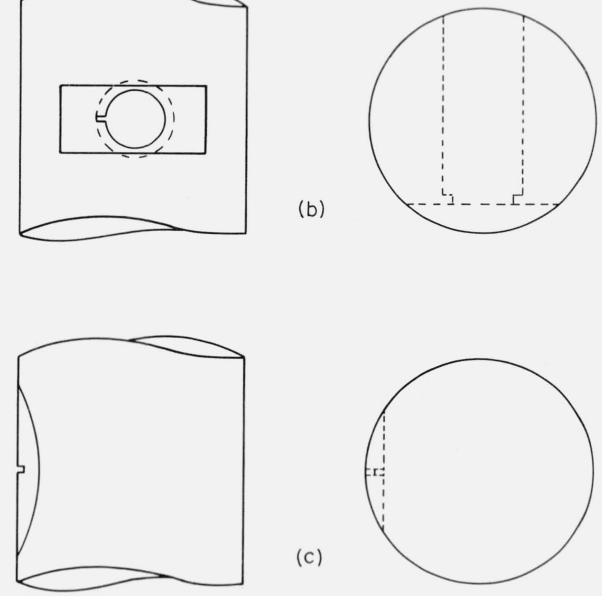

FigURE 5. Fiducial marks: (a) $0.020 \mathrm{~mm}$ tungsten wire tied taut around the specimen; $(b)$ platinum specimen; $(c)$ sapphire specimen.

A promising method of tying two $0.020 \mathrm{~mm}$ tungsten wires taut around the specimen was tried, see figure 5 (a). Each wire crossed in front of a $1.5 \mathrm{~mm}$ diam hole drilled in the specimen and was held in position by running through grooves on either side of the hole. When the furnace became hot enough that the wires were self illuminating they stood out sharply against the dark background and precise settings, within \pm 0.7 micrometers, with the filar eyepiece could be made. At temperatures above $1500{ }^{\circ} \mathrm{C}$, however, probably because of recrystallization, the wires grew in length and warped. Because they were no longer straight any further readings could not be relied upon.

It has been found that small holes (of the order of $0.25 \mathrm{~mm}$ ) drilled through a specimen [13] or small nicks or grooves [14] will serve as reliable fiducial marks. It is sometimes difficult, however, to obtain a round hole that is small enough for high precision measurements.

Satisfactory fiducial marks were finally made by placing a small symmetrical nick at the edge of the specimen. This was done for the platinum specimen, see figure 5 (b), by drilling a $1.73 \mathrm{~mm}$ hole radially into the rod to within about $0.25 \mathrm{~mm}$ of penetrating a milled flat on the opposite surface. A second hole of $1.57 \mathrm{~mm}$ diam, concentric with the first hole, was drilled in the flat, penetrating through to the larger diameter hole. This left a thin ring around the inside of the hole and a small nick was placed in the ring with a hardened steel ruling edge to serve as a fiducial mark. In the case of the sapphire specimen, see 
figure 5 (c), a local area on one side was ground with a diamond wheel until a thin ridge was left, the faces of which were parallel to the axis of the specimen. A small nick was then placed in the ridge with a 0.25 $\mathrm{mm}$ carbide disk as a fiducial mark. The precision of setting the cross hairs on these marks was found to be comparable to that of setting on the tungsten wires.

\section{Procedure}

With the specimen in the furnace and the furnace sealed the vacuum pumps were turned on and the pressure reduced to about $1 \times 10^{-5}$ torr. Power was applied slowly to heat the specimen. When the desired temperature was reached the optimum temperature gradient was obtained by adjusting the power supplied to the two heating sections at either end. This condition was held for $10 \mathrm{~min}$ to allow the specimen to stabilize. A longer stabilizing period was not necessary since it was found that no change in length of the specimen could be detected after a 5 min wait. The microscopes were focused on the specimen by adjusting the position of the comparator and on the reference scale by adjusting its position. The emf of the two absolute thermocouples was determined with a potentiometer to the nearest microvolt and the brightness temperature of the specimen was measured using the disappearing filament optical pyrometer. Five settings with each microscope were made in turn on the specimen, the reference scale, and again on the specimen. Finally, the temperature measurements were repeated.

\section{Discussion}

Although care has been exercised in measurement of temperature and length, errors inherent in any system operating at these temperatures restrict the accuracy in the measurement of these values and the determination of the coefficient of expansion. An error in temperature measurement of $1{ }^{\circ} \mathrm{C}$ in a specimen having a coefficient of $10 \times 10^{-6} /{ }^{\circ} \mathrm{C}$ is equivalent to an error in length measurement of 10 micrometers/ meter. Also, an error in temperature measurement of $1{ }^{\circ} \mathrm{C}$, or in length measurement of one micrometer in a specimen $10 \mathrm{~cm}$ long having a coefflcient of $10 \times 10^{-6} /{ }^{\circ} \mathrm{C}$ and heated over a temperature range of $100{ }^{\circ} \mathrm{C}$, will result in an error of less than $\pm 0.1 \times 10^{-6} /$ ${ }^{\circ} \mathrm{C}$ in the determination of the coefficient.

Uncertainties in temperature measurements may arise from a shift in calibration of the thermocouples through contamination and aging. Although highpurity alumina $\left(99 \% \quad \mathrm{Al}_{2} \mathrm{O}_{3}\right)$ has been used for thermocouple insulation the trace impurities can affectively change the output of the thermocouples. To reduce the effect of this and other possible sources of error the following procedure was used: (1) The probe thermocouple was calibrated by the Temperature Physics Section of the National Bureau of Standards, (2) the absolute thermocouples were calibrated by comparison with the probe thermocouple, (3) the expansion tests were conducted, (4) the absolute thermocouples were again calibrated, and (5) the probe thermocouple was again calibrated. This procedure demonstrated that the uncertainties in temperature measured during the thermal expansion tests did not exceed $2 \mathrm{deg}$ at $800{ }^{\circ} \mathrm{C}$ and $4 \mathrm{deg}$ at $1600{ }^{\circ} \mathrm{C}$. The standard deviation of the differences between the temperatures indicated by the two absolute thermocouples was $1.5^{\circ} \mathrm{C}$, and that of the average of the two readings is $0.7^{\circ} \mathrm{C}$.

Preliminary results ${ }^{2}$ have been obtained on specimens of platinum and sapphire. Figure 6 indicates the difference (residuals) between observed expansion of these materials and the expansion calculated from quadratic equations fitted to the data by the method of least squares. For the platinum and sapphire specimens the standard deviations computed from the residuals are 23 and 27 micrometers/meter respectively.

From these estimates of the precision of the temperature measurements, $\pm 0.7^{\circ} \mathrm{C}$, and of the expansion measurements, \pm 23 and \pm 27 micrometers/meter, the precision of the length measurements expressed as standard deviations are 2.1 and 2.6 micrometers, respectively.

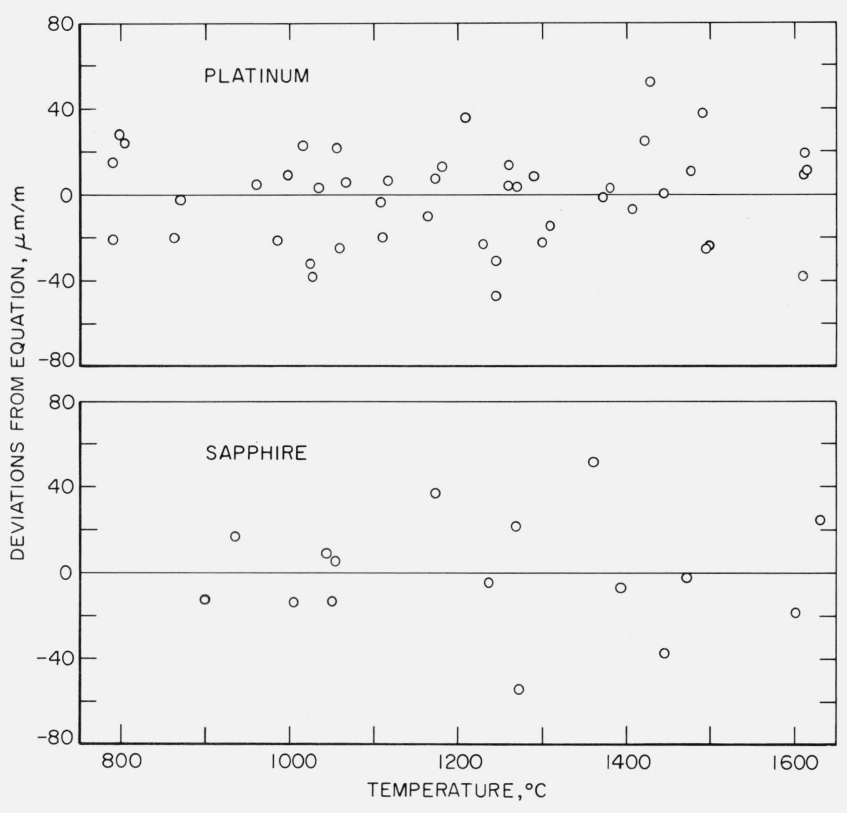

Figure 6. A plot of the differences between observed expansion and the expansion calculated from an equation fitted to the data by the method of least squares.

Assuming that the accuracy and precision of the length measurements are comparable and the uncertainties in the temperature measurements are as previously stated, thermal expansion measurements made with this equipment can be estimated to be

2 A complete report on these measurements will be made after the investigation has been completed. 
accurate within \pm 30 micrometers/meter at $800{ }^{\circ} \mathrm{C}$ and within \pm 50 micrometers $/$ meter at $1600{ }^{\circ} \mathrm{C}$.

It was discovered that a small wedge $(6 \mathrm{~min})$ between the faces of each vitreous silica window contributed an error in the measurement of expansion from room temperature. Since the measurement of initial length is made with the specimen outside the furnace there is no precise measurement of the change in length of the specimen from room temperature to $900{ }^{\circ} \mathrm{C}$ where the specimen is self illuminating. This error was virtually constant for a fixed position of the window, however, and did not significantly affect the determination of the coefficient of expansion at the operating temperature. To eliminate this and other possible errors two higher quality windows are being made that will have surfaces flat to $l$ wavelength of visible light and parallel to 1 sec.

Light sources are also being placed in the furnace so that the length of the specimen can be determined inside the furnace at ambient and intermediate temperatures.

With the improvements discussed in the previous paragraphs and the preliminary results obtained on platinum and sapphire it is believed that the apparatus and the procedure described in this paper will yield important and useful thermal expansion data on high temperature materials.

The authors thank L. Frenkel for contributions made in the design of the apparatus and to T. A. Hahn for helpful discussions.

\section{References}

[1] S. D. Mark, Jr. and R. C. Emannelson, A thermal expansion apparatus with a silicon carbide dilatometer for temperatures to $1500{ }^{\circ} \mathrm{C}$, Bull. Am. Ceram. Soc. 3 7, 193 (1958).
[2] W. J. Campbell, Platinum expansion values for thermal calibration of high-temperature x-ray diffraction cameras and diffractometers, U.S. Bureau of Mines Information Circular 8107 (1962).

[3] R. G. Merryman and C. P. Kempter, Precise temperature measurements in Debye-Scherrer specimens at elevated temperatures, J. Am. Ceram. Soc. 48, 202 (1965).

[4] R. D. Fouchaux and R. O. Simmons, Measurements of thermal expansion and thermal equilibrium defects in silver chloride, Phys. Rev. 136, 1664 (1964).

[5] Z. S. Basinski, W. Hume-Rothery, and A. L. Sutton, The lattice expansion of iron, Proc. Roy. Soc. London A229, 459 (1955).

[6] A. Schauer, Thermal expansion, Grueneisen parameter, and temperature dependence of lattice vibration frequencies of aluminum oxide, Can. J. Phys. 43, 523 (1965).

[7] J. Otto and W. Thomas, Die Thermische Ausdehnung von Quarzglas im Temperaturbereich von 0 bis $1060{ }^{\circ} \mathrm{C}, \mathrm{Z}$. Physik 175, 337 (1963).

[8] N. S. Rasor and J. D. McClelland, Thermal property measurements at very high temperatures, Rev. Sci. Instr. 31, 595 (1960).

[9] I. B. Fieldhouse, J. C. Hedge, and J. I. Lang, Measurements of thermal properties, Wright Air Development Center Technical Report 58-274, ASTIA Document No. 206892 (1958).

[10] H. W. Deem, W. D. Wood, and C. F. Lucks, Thermal properties of materials at elevated temperatures, Wright Air Development Center Technical Report 59-215, ASTIA Document No. 233182 (1959).

[11] B. R. Micciole and P. T. B. Shaffer, High-temperature thermal expansion behavior of refractory materials: 1 . Selected monocarbides and binary carbides, J. Am. Ceram. Soc. 47, 351 (1964).

[12] O. J. Whittemore, Jr. and N. N. Ault, Thermal expansion of various ceramic materials to $1500{ }^{\circ} \mathrm{C}$, J. Am. Ceram. Soc. 39, 443 (1956).

[13] J. B. Conway, Properties of some refractory metals, GEMP-375 General Electric, June 29, 1965.

[14] C. J. Engberg and E. H. Zehms, Thermal expansion of $\mathrm{Al}_{2} \mathrm{O}_{3}$, $\mathrm{BeO}, \mathrm{MgO}, \mathrm{B}_{4} \mathrm{C}, \mathrm{SiC}$, and $\mathrm{TiC}$ above $1000{ }^{\circ} \mathrm{C}, \mathrm{J}$. Am. Ceram. Soc. 42, 300 (1959).

(Paper 71C2-247) 